$\Delta$ rrkivoc

Free to Authors and Readers
A Platinum Open Access Journal

for Organic Chemistry
Paper

Arkivoc 2021, part x, 64-76

\title{
Copper(II)-catalyzed aerobic oxidation of hydrazides to azo intermediates and their Diels-Alder versus ene trapping
}

\author{
Duangduan Chaiyaveij ${ }^{a *}$ and Andrew Whiting ${ }^{b^{*}}$
}

${ }^{a}$ Chemistry Department, Faculty of Science and Technology, Thammasat University, Khlong Luang, Pathum Thani, 12120, Thailand

${ }^{b}$ Centre for Sustainable Chemical Processes, Department of Chemistry, Durham University, Science

Laboratories, South Road, Durham, DH1 3LE, UK

Email: chaiyavech@hotmail.com; andy.whiting@durham.ac.uk

Received 07-26-2021

Accepted Manuscript 10-11-2021

Published on line 11-07-2021

\section{Abstract}

The oxidation of diethyl 1,2-hydrazinedicarboxylate using a catalytic $\mathrm{Cu}$ (II)-oxazoline system occurs at RT in air, resulting in azo generation, which can then be trapped in situ via hetero-Diels-Alder (HDA) and competitive ene-reactions, with chemoselectivity being both temperature and solvent dependent. The procedure was extended to other azo systems and mechanism studies are reported.

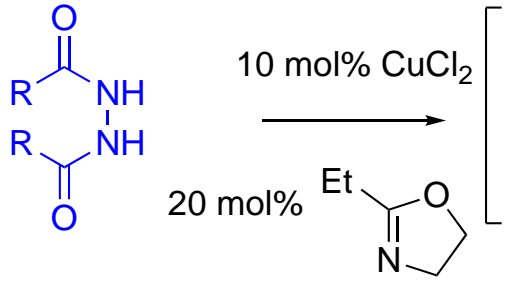

$\mathrm{O}_{2}$, solvent

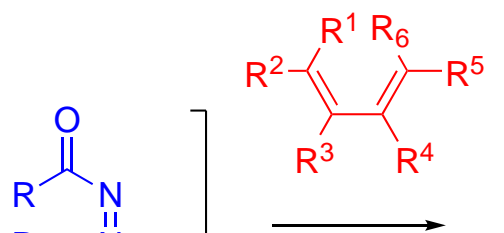

Azo-Diels-Alder reaction<smiles>[R]C(=O)N1C([R7])[C@H]([R7])C([R8])=C([R7])[C@]1([R7])[2H]</smiles>

azo-ene reaction

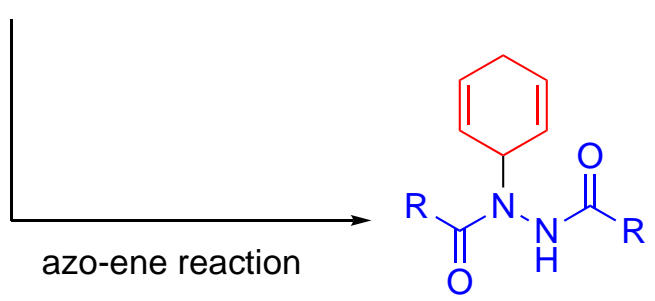

Keywords: Hetero-Diels-Alder reaction, azo, ene-reaction, copper(II)-catalyzed aerobic oxidation 


\section{Introduction}

The reaction of azo dienophiles with conjugated dienes via a [4+2]-cycloaddition is over a century old ${ }^{1-3}$ and it was one of first examples of a hetero-Diels-Alder (HDA) reaction. This reaction has been used extensively in organic synthesis as a powerful synthetic route to 1,4 -diamines; ${ }^{4,5}$ which are biologically active compounds present in many protease inhibitors; ${ }^{6,7}$ and have potential for the preparation of antitumor agents. ${ }^{8}$ The formation of azo dienophiles from hydrazines employs harsh conditions, e.g. fuming $\mathrm{HNO}_{3}$ or oxidation by using halogens, ${ }^{9,10}$ and hence, there is a need to develop mild, clean, sustainable catalytic conditions for the oxidation of hydrazines directly to azo compounds. This system is very similar to the generation of diimide from hydrazine with molecular oxygen. ${ }^{11}$ We set out to develop new methods to achieve this reaction, preferably developing conditions where the oxidant was air. Indeed, our previous work reported a $\mathrm{CuCl}_{2}$-2-ethyl-2-oxazoline catalytic system which operated at RT and oxidized hydroxamic acids to acyl nitroso species, which were trapped in situ by various dienes (the intermediate nitroso species were not isolable). ${ }^{12,13}$ We therefore hypothesized that this system might also be applicable to the oxidation of hydrazines to the corresponding azo species, since acylhydrazides are expected to be directly analogous to hydroxamic acids and should oxidize similarly. An initial demonstration of this was exemplified by generating an azo compound that was directly trapped intramolecularly by a diene in situ in excellent yield. ${ }^{12,13}$ Although it has been recently shown that certain copper complexes can be used as mild oxidation systems for a number of related reactions, ${ }^{14-20}$ the copper-catalyzed aerobic oxidation of hydrazines and hydrazides to the corresponding azo compounds remains largely unexplored, with one example back in $1948^{21}$ using catalytic $\mathrm{CuBr}$ and di-tert butyldiaziridinone as oxidant was reported, however, the resulting azobenzene did not undergo HDA trapping. ${ }^{22}$ It has also been recently reported that a Cul-DMAP system oxidizes di-tert-butylhydrazodicarboxylate to the corresponding azodicarboxylate which was used in situ to dehydrogenate 1,2,3,4-tetrahydroquinolines. ${ }^{23}$ However, these oxidation conditions were not suitable for the in situ hetero-Diels-Alder reaction. There is, therefore, a clear need to develop an efficient, general, robust, clean, aerobic and catalytic oxidative route to azo compounds directly from hydrazides, and herein, we report the use of a $\mathrm{CuCl}_{2}$-2-ethyl-2-oxazoline catalyst system for this oxidation which is diene compatible, allowing efficient HDA trapping in situ.

\section{Results and Discussion}

The reaction of diethyl azodicarboxylate (DEAD) with 1,3- cyclohexadiene is known to result in competing outcomes through HDA and ene pathways ${ }^{24-27}$ forming two products, i.e. 4 a and $\mathbf{5 a}$. Initial attempts at developing an aerobic oxidation of hydrazine 1 were focused upon this reaction to examine the HDA:ene ratio in various solvents, as shown in Scheme 1 and corresponding results in Table 1. 
<smiles>CCOC(=O)NNC(=O)OCCC1CC2C=CC(C1)N2C(=O)OCC</smiles>

Scheme 1. Azo-dienophile generation and trapping with cyclohexadiene.

Table 1. Solvent effects for the aerobic oxidation of 1 followed by trapping with 3a

\begin{tabular}{cccccc}
\hline Entry & Solvent & Temp. $\left({ }^{\circ} \mathrm{C}\right)$ & Time $(\mathrm{h})$ & Ratio $^{\mathrm{a}}$ 4a:5a & Yield $^{\mathrm{b}}(\%)$ \\
\hline 1 & $\mathrm{MeOH}^{\mathrm{a}, \mathrm{c}}$ & $\mathrm{rt}$ & 240 & $29: 71$ & 7 \\
2 & $\mathrm{MeCN}^{\mathrm{b}}$ & $\mathrm{rt}$ & 96 & $36: 64$ & 56 \\
3 & $\mathrm{EtOH}^{\mathrm{a}, \mathrm{c}}$ & $\mathrm{rt}$ & 240 & $32: 68$ & 5 \\
4 & EtOAc $^{\mathrm{a}, \mathrm{c}}$ & $\mathrm{rt}$ & 240 & $35: 65$ & 10 \\
5 & Toluene $^{\mathrm{b}}$ & reflux & 6 & $74: 26$ & 87 \\
6 & $\mathrm{MeOH}^{\text {:oluene, } 1: 4^{\mathrm{a}, \mathrm{c}}}$ & $\mathrm{rt}$ & 240 & $45: 55$ & 4 \\
7 & $\mathrm{CHCl}_{3} *^{\mathrm{a}}$ & $\mathrm{rt}$ & 48 & $29: 71$ & 86 \\
\hline
\end{tabular}

antegration at using the signals at 6.70-6.45 to 5.94 (=C-H resonances in $\mathbf{4 b}$ and $\mathbf{5 b}$ respectively). bIsolated yield after purification (see Supporting Information).

The results from Table 1 clearly show that the ratio between cycloadduct $4 a$ and ene product $5 a$ varied as a function of solvent. Reactions carried out in $\mathrm{MeOH}$ and $\mathrm{CHCl}_{3}$ gave more ene adduct 5a compared to cycloadduct 4a (71:29, Entries 1 and 7, Table 1), whereas in toluene (reflux), more cycloadduct 4a than ene 5a (74:26) was observed and the reaction finished in $6 \mathrm{~h}$ (Entry 5, Table 1). However, even though $\mathrm{MeOH}$ gave good ene to HDA selectivity, the yield was poor (7\%) and the reaction failed to go to the completion. The reaction in MeCN (reflux) gave good HDA chemoselectivity in the nitroso system, ${ }^{12,13}$ but was considerably less selective in the azo application, giving only a 36:64 ratio of cycloadduct $4 \mathrm{a}$ to ene $\mathbf{5 a}$. EtOH, EtOAc and a mixed solvent of $\mathrm{MeOH} /$ toluene (1:4) all gave reactions which did not complete even after $10 \mathrm{~d}$. These reactions showed that the two best solvent systems were $\mathrm{CHCl}_{3}(\mathrm{RT})$ and toluene (reflux), since both of these reactions (Entries 7 and 5, Table 1) resulted in good yields and chemoselectivities. The higher temperature toluene conditions particularly gave the HDA adduct with superior selectivity over the $\mathrm{CHCl}_{3}$ conditions. After optimization of the solvent/reaction conditions, various dienes were then tested using the two main methods developed, as shown in Scheme 2 and Table 2 


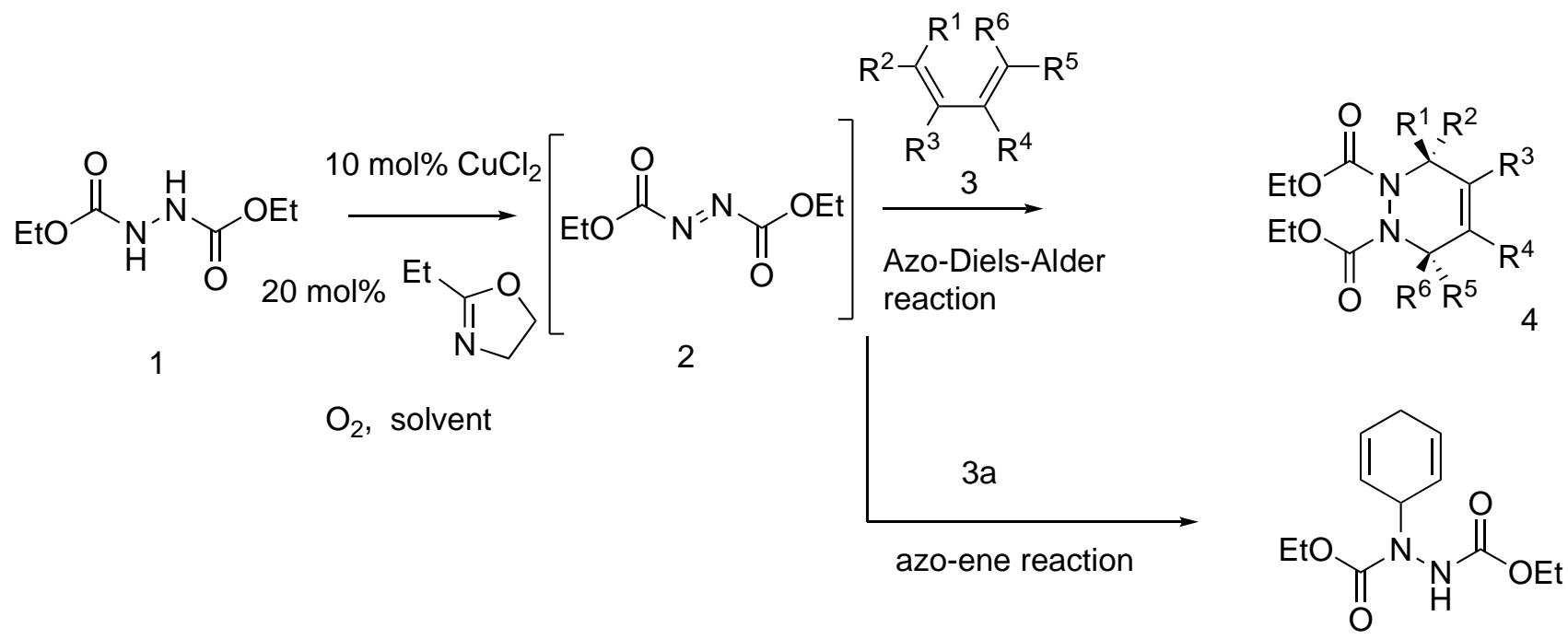

Scheme 2. Azo-dienophile generation and trapping with various dienes.

It is interesting to note from Table 2, that the chemoselectivity of the azo dienophile reaction in general with different dienes differed from that found previously with the nitroso systems. ${ }^{12,13}$ For example, for the nitroso reaction with 1,3-cyclohexadiene, no ene product was observed and only HDA was obtained. In contrast, in the azo system, there was both ene and HDA adducts were obtained (Entry 1, Table 2). Also, in the nitroso system, 12,13 isoprene and 2,3-dimethyl-1,3-butadiene gave both ene and HDA products, whereas in the azo system, the ene products were not observed (Entries 5 and 3, Table 2). For 10-dimethylanthracene and 1,4-diphenyl-buta1,3-diene $\left(\mathrm{CHCl}_{3} \mathrm{RT}\right)$, neither reaction went to completion, even after 10 and $15 \mathrm{~d}$, respectively. Also, reaction times varied from 6-96 h, which shows that the oxidation was slower than the nitroso system. However, when these reactions were carried out in toluene (reflux), they completed in $96 \mathrm{~h}$, giving 30 and $47 \%$ yields, respectively. In fact, the reaction in toluene generally gave better yields and was significantly faster than in $\mathrm{CHCl}_{3}$, except for cyclopentadiene where the yield was poor due to the competing dimerization of the cyclopentadiene at the higher temperature (Entry 1, Table 2). Interestingly, all the azo cycloadducts in Table 2 when initially analyzed in $\mathrm{CDCl}_{3}$ by ${ }^{1} \mathrm{H}$ NMR at $\mathrm{RT}$, all the spectra were not easily interpreted due to the broadness and complexity of the signals. Hence, higher temperatures $\left(25-80^{\circ} \mathrm{C}\right)$ in $d_{6}$-DMSO were required to allow sharper spectra to be obtained (see Figure 1 for $4 c$, for example). 
Table 2. Products and isolated yields for the in situ azo dienophile generation and Diels-Alder vs. ene trapping

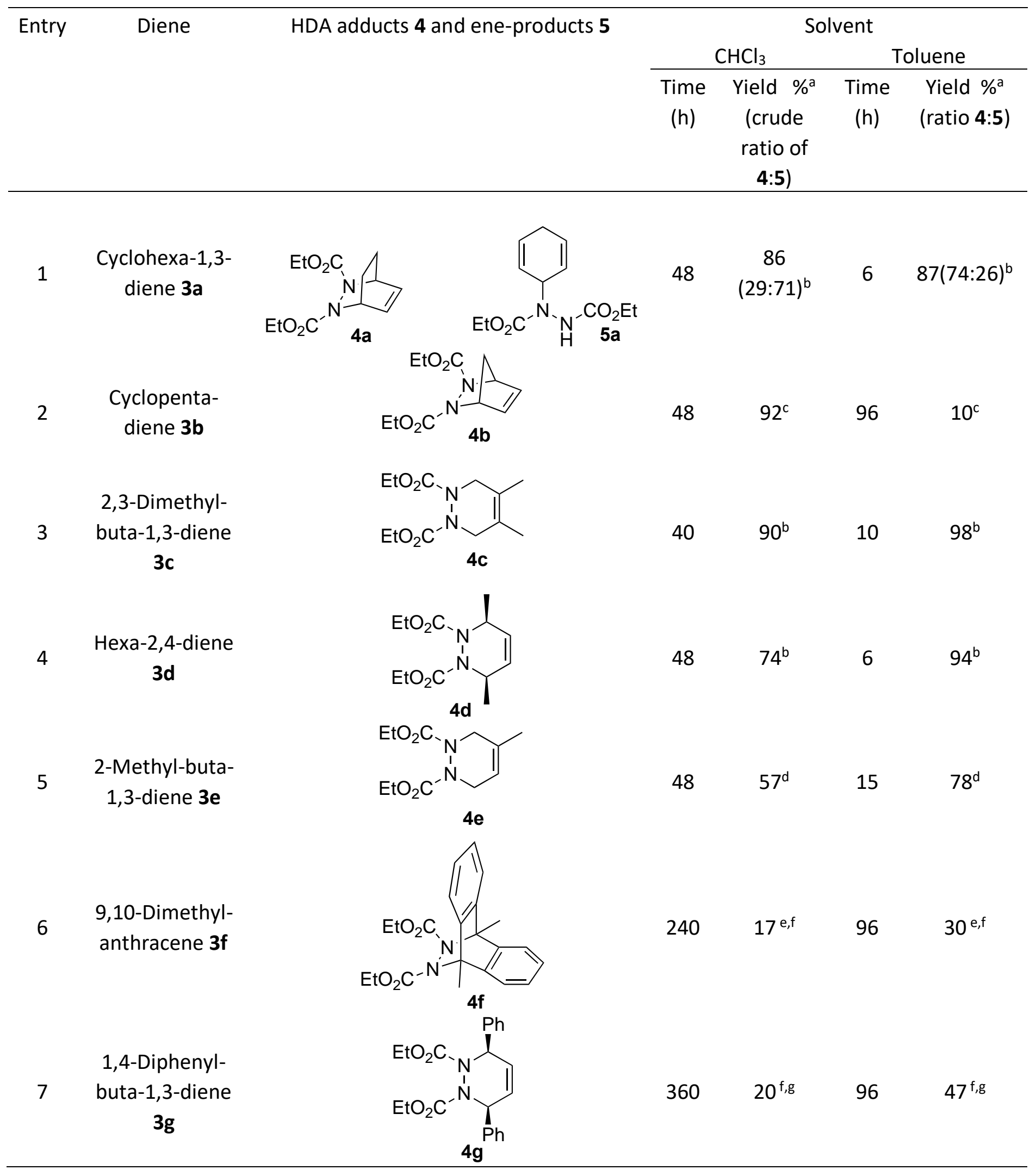

asolated yields after purification (see Supporting Information). 'bee references 24-27. 'See references 28,29.

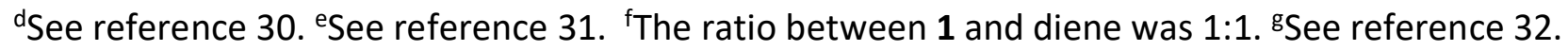




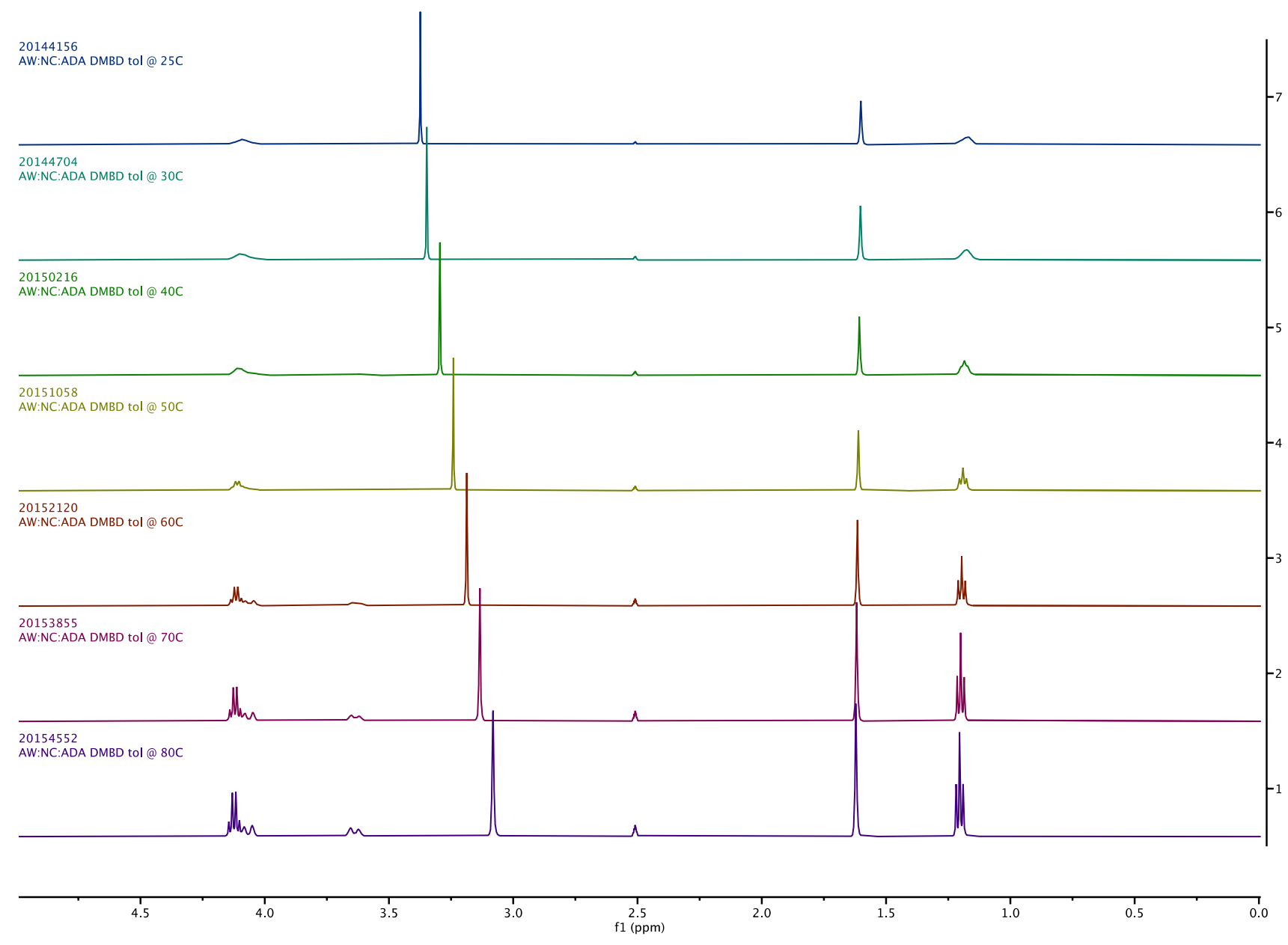

Figure 1. ${ }^{1} \mathrm{H}$ NMR of the cycloadduct $4 \mathrm{c}$ in $d_{6}$-DMSO at various temperatures.

Having shown that the azo dicarboxylate system could be generated in situ (Table 1), other hydrazine analogues were examined. Firstly, applying the optimized conditions on 1,2-diphenylhydrazine 6 reacting with 1,3-cyclohexadiene (Scheme 3), no cycloadduct was observed from azo trapping by cyclohexadiene. Indeed, after 45 mins, azobenzene 7 was obtained (86\%) together with small amounts of aniline. ${ }^{33}$ This reaction shows that the azo compound was generated under the reaction conditions, but azo benzene is a poor dienophile, and does not trap efficiently. ${ }^{9}$ Also, aniline formation suggested that after the azo-benzene is formed, it is then reduced. Moreover, aniline can react with $\mathrm{Cu}(\mathrm{I})$ to form the azo compound. ${ }^{34}$ Hence, we examined diethyl hydrazinedicarboxylate $\mathbf{1}$ without diene present under the same conditions but there was no azo compound $\mathbf{2}$ produced according to TLC and starting material was recovered. 


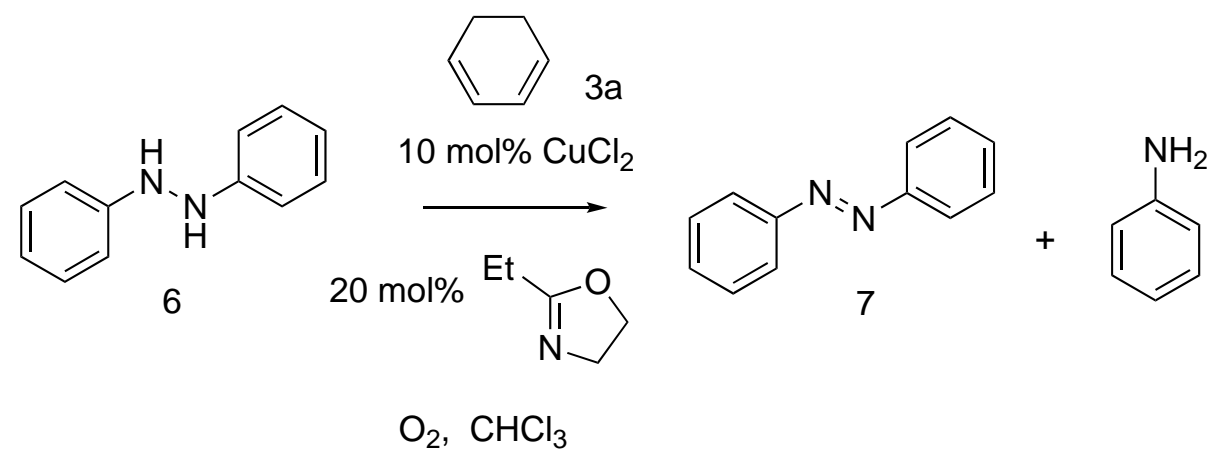

Scheme 3. Attempts to oxidise diphenylhydrazine and trap with cyclohexadiene.

Next, the optimized catalytic conditions were employed on a system which might be more amenable to azoformation and HDA trapping, i.e. the in situ oxidation of 4-phenylurazole 8 to 4-phenyl-1,2,4-trizoline-3,5-dione (PTAD) 9 which was trapped by various dienes to yield the cycloadducts 10 (Table 3).<smiles>O=c1[nH][nH]c(=O)n1-c1ccccc1</smiles>

8

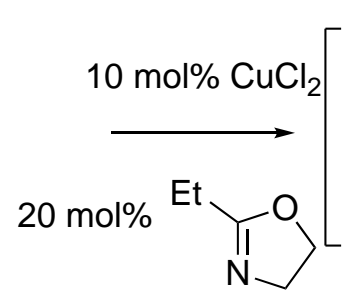

$\mathrm{O}_{2}$, solvent

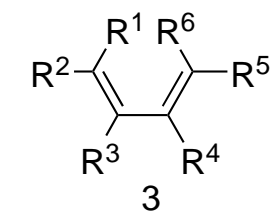

Azo-Diels-Alder reaction<smiles>[R7]C1=C([R7])[C@H](P)n2c(=O)n(-c3ccccc3)c(=O)n2C1[R7]</smiles>

10

Scheme 4. Application of the oxidation-trapping sequence on 4-phenylurazole.

Table 3. In situ azo generation and Diels-Alder trapping

\begin{tabular}{|c|c|c|c|c|c|}
\hline Entry & Diene & HDA adduct 10 & Solvent & $\begin{array}{c}\text { Time } \\
\text { (h) }\end{array}$ & $\begin{array}{l}\text { Yield } \\
(\%)^{\mathrm{a}}\end{array}$ \\
\hline \multirow{2}{*}{1} & & & $\mathrm{CHCl}_{3}$ & 6 & $94^{b, c}$ \\
\hline & & & $\mathrm{MeOH}$ & 5 & $96^{b, c}$ \\
\hline \multirow{2}{*}{2} & & & $\mathrm{CHCl}_{3}$ & 5 & $94^{b}$ \\
\hline & & $O 10 b$ & $\mathrm{MeOH}$ & 5 & $96^{b}$ \\
\hline
\end{tabular}


Table 3. Continued

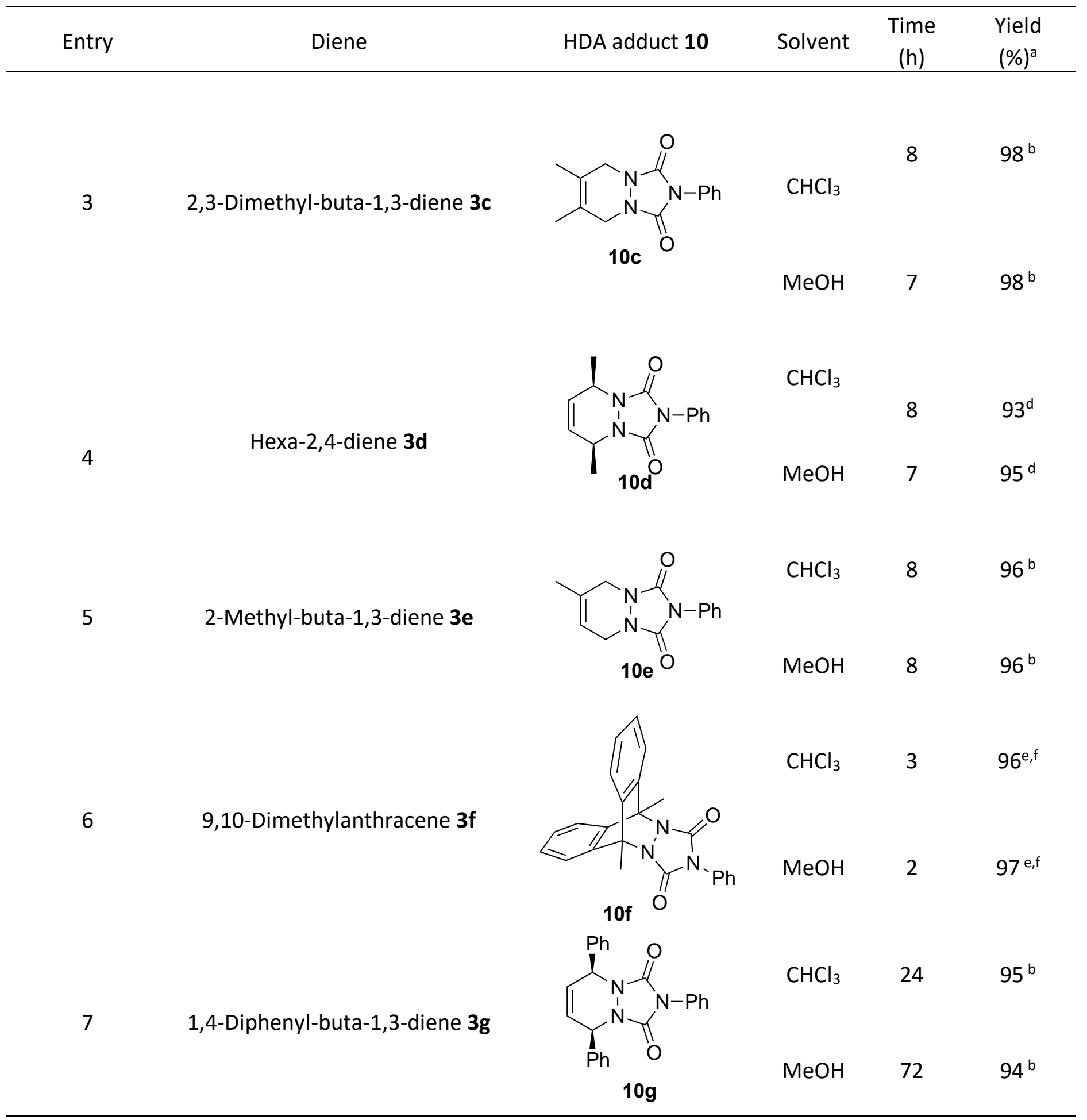

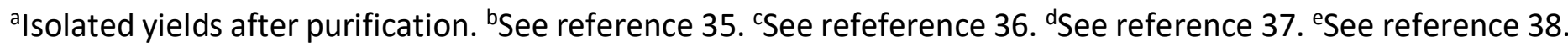
fSee reference 39.

The results in Table 3, showed that the oxidation of 4-phenyl urazole 8 to PTAD 9 using the Cuoxazoline system worked well in both chloroform and methanol. The yield of cycloadducts was universally high (93-98\%) and the reaction time varied from 2-72 hours. The reaction of 8 with diene $\mathbf{g}$ in methanol took the longest time to finish (Table 3, entry 7). This was due to the poor solubility of the 
diene in methanol. However, diene $3 \mathbf{f}$ was not sufficiently soluble in methanol, the reaction time was only 2 hours (Table 3, entry 6). The cycloadduct from this reaction was insoluble in methanol, therefore, the purification was a simple filtration.

\section{Conclusions}

An efficient, mild and green catalytic aerobic oxidation of hydrazide to azo derivative has been developed. This method can generate azo compounds in situ, which are readily trapped by a diene present in the reaction to form the corresponding cycloadducts in low to excellent yields depending upon the nature of the diene. The chemoselectivity of this reaction depends upon the reaction conditions and solvent. The reaction in toluene under reflux gave the best cycloadduct selectivity, whereas the reaction in chloroform gave the best ene selectivity.

\section{Experimental Section}

General. Reactions were performed in the presence of air. All reagents were purchased from Aldrich and used as received. Solvents (AR grade) were used as received. ${ }^{1} \mathrm{H}$ NMR and ${ }^{13} \mathrm{C}\left\{{ }^{1} \mathrm{H}\right\}$ spectra were recorded using a Bruker Avance 400 operating at $400 \mathrm{MHz}$ for ${ }^{1} \mathrm{H}$ NMR and ${ }^{13} \mathrm{C}$ NMR at $101 \mathrm{MHz}$, or for ${ }^{1} \mathrm{H}$ NMR recorded at 500 $\mathrm{MHz}$ using a Bruker DRX 500 spectrometer. $\mathrm{CDCl}_{3}$ and $d_{6}$-DMSO were used as the solvent for all samples. ${ }^{1} \mathrm{H}$ NMR chemical shifts are reported with reference to TMS using residual proton on non deuterated solvent $\left(\mathrm{CDCl}_{3}: 7.26 \mathrm{ppm}\right)$ whereas ${ }^{13} \mathrm{C} \mathrm{NMR}$ spectra are reported with reference to TMS using the carbon signals of the deuterated solvent $\left(\mathrm{CDCl}_{3}\right.$ : $\left.77.23 \mathrm{ppm}\right)$. Elemental analysis was performed using an Exeter Analytical E440 machine by departmental service at Durham University. All chromatography was carried out using silica gel (Silicagel LC60A 40-63 $\mu \mathrm{m}$ ) which obtained from Fluorochem. The removal of solvent was performed on a rotary evaporator in vacuum. IR spectra were recorded with a Perkin-Elmer 1615 FTRIR spectrometer. Melting points were determined using an Electrothermal melting point apparatus. Low resolution mass spectrometry was carried out on a Waters TQD equipped with Acquity UPLC and an electrospray ion source and high resolution mass spectrometry on a Waters LCT Premier XE equipped with Acquity UPLC and a lock-mass electrospray ion source.

General procedure for solvent screening for the in situ azo-generation-Diels-Alder reaction using diethyl hydrazinedicarboxylate and trapping with 1,3-cyclohexadiene (Table 1). To $20 \mathrm{~mL}$ of solvent, $2.30 \mathrm{mmol}$ of 1,3-cyclohexadiene, $10 \mathrm{~mol} \% \mathrm{CuCl}_{2}$ and $20 \mathrm{~mol} \%$ 2-ethyl-2-oxazoline was added, followed by $1.15 \mathrm{mmol}$ of diethyl hydrazinedicarboxylate 1 . The resulting solution was stirred at room temperature in air and was monitored by TLC. The completion of the reaction was confirmed by the disappearance of the starting material. The solvent was removed by evaporation and the crude product was purified by silica gel chromatography (hexane: ethyl acetate, $4: 1 \mathrm{v} / \mathrm{v}$ as the eluent).

General procedure for the in situ azo-generation-Diels-Alder reaction using diethyl hydrazinedicarboxylate with various dienes in chloroform (Table 2). To a $\mathrm{CHCl}_{3}(20 \mathrm{ml})$ solution of $2.30 \mathrm{mmol}$ of appropriate diene, 10 $\mathrm{mol} \% \mathrm{CuCl}_{2}$ and $20 \mathrm{~mol} \%$ 2-ethyl-2-oxazoline was added $1.15 \mathrm{mmol}$ of diethyl hydrazinedicarboxylate 1 . The resulting solution was stirred at room temperature in air and was monitored by TLC. The completion of the 
reaction was confirmed by the disappearance of the starting material. The solvent was removed by evaporation and the crude product was purified by silica gel chromatography (hexane: ethyl acetate, $4: 1 \mathrm{v} / \mathrm{v}$ as the eluent).

Example procedure for the in situ azo-generation-Diels-Alder reaction using diethyl hydrazinedicarboxylate with various dienes in toluene under reflux. To a toluene $(20 \mathrm{ml})$ solution of 1,3-cyclohexadiene $(188 \mathrm{mg}, 2.35$ $\mathrm{mmol}$ ), $\mathrm{CuCl}_{2}$ (16 mg, $0.12 \mathrm{mmol}$ ) and 2-ethyl-2-oxazoline (24 mg, $0.24 \mathrm{mmol}$ ) was added diethyl hydrazinedicarboxylate $(207 \mathrm{mg}, 1.18 \mathrm{mmol})$. The resulting solution was stirred under reflux in air and was monitored by TLC. The completion of the reaction was confirmed by the disappearance of the starting material. The reaction was stirred for $6 \mathrm{~h}$. The solvent was removed by evaporation and the crude product was purified by silica gel chromatography (hexane: ethyl acetate, $4: 1 \mathrm{v} / \mathrm{v}$ as the eluent), giving $4 \mathbf{4 a}(192 \mathrm{mg}, 64 \%)$ and $5 \mathrm{a}$ (68 $\mathrm{mg}, 23 \%$ ). The ratio of $4 \mathrm{a}$ to $5 \mathrm{a}$ was determined on the crude product by ${ }^{1} \mathrm{H}$ NMR using the signals at $\delta 6.70-6.45$ to 5.94 (=C-H resonances in $\mathbf{4 a}$ and $\mathbf{5 a}$ respectively). Analytical and spectroscopic data were identical to those reported in the literature. ${ }^{1,24,25}$

Procedure for the azo-generation reaction using 1,2-diphenylhydrazine in chloroform. To a $\mathrm{CHCl}_{3}(20 \mathrm{ml})$ solution of $\mathrm{CuCl}_{2}(34 \mathrm{mg}, 0.25 \mathrm{mmol}$ ) and 2-ethyl-2-oxazoline (50 mg, $0.50 \mathrm{mmol}$ ) was added 1,2diphenylhydrazine (463 $\mathrm{mg}, 2.51 \mathrm{mmol}$ ). The resulting solution was stirred at RT in air and was monitored by TLC. The completion of the reaction was confirmed by the disappearance of the starting material. The reaction was stirred for 45 minutes. The solvent was removed by evaporation and the crude product was purified by silica gel flash chromatography (hexane: ethyl acetate, 1:1 v/v as the eluent), giving 7 as orange solid (394 mg, $86 \%) ; \mathrm{mp} 74-75.5^{\circ} \mathrm{C}$ (lit. $66-67.5^{\circ} \mathrm{C}$ ). Analytical and spectroscopic data were identical to those reported in the literature ${ }^{40,41}$

General procedure for the in situ azo-generation-Diels-Alder reaction using 4-phenylurazole with various dienes in chloroform (Table 3). To a $\mathrm{CHCl}_{3}(20 \mathrm{ml})$ solution of the appropriate diene, $10 \mathrm{~mol} \%$ of $\mathrm{CuCl}_{2}$ and 20 mol \% of 2-ethyl-2-oxazoline was added 4-phenylurazole 8. The resulting solution was stirred at room temperature in air and was monitored by TLC. The completion of the reaction was confirmed by the disappearance of the starting material. The solvent was removed by evaporation and the crude product was purified by flash silica gel chromatography (hexane: ethyl acetate, 1:1 v/v as the eluent).

Example procedure for the in situ azo-generation-Diels-Alder reaction using 4-phenylurazole with various dienes in methanol. To a methanol $(20 \mathrm{ml})$ solution of cyclohexa-1,3-diene (186 mg, $2.32 \mathrm{mmol}), \mathrm{CuCl}_{2}(16 \mathrm{mg}$, $0.12 \mathrm{mmol}$ ) and 2-ethyl-2-oxazoline $(23 \mathrm{mg}, 0.23 \mathrm{mmol}$ ) was added 4-phenylurazole (204 $\mathrm{mg}, 1.16 \mathrm{mmol})$. The resulting solution was stirred at room temperature in air and was monitored by TLC. The completion of the reaction was confirmed by the disappearance of the starting material. The reaction was stirred for $5 \mathrm{~h}$. The solvent was removed by evaporation and the crude product was purified by silica gel flash chromatography (hexane: ethyl acetate, 1:1 v/v as the eluent), giving $10 \mathrm{a}$ (350 mg, 96\%); mp 177-178 ${ }^{\circ} \mathrm{C}$. Analytical and spectroscopic data were identical to those reported in the literature. ${ }^{35,39}$

\section{Acknowledgements}

DC thanks to the Research Fund for DPST Graduate with First Placement grant number 12/2557, Prof. Dr. Nantanit Wanitchacheva, Funding for knowledge improvement overseas Thammasat University, NMR service at Durham University for the VT NMR and MS service at Durham University for LRMS and HRMS. 


\section{Supplementary Material}

Experimental procedures, analytical data and copies of ${ }^{1} \mathrm{H},{ }^{13} \mathrm{C}$ NMR spectra can be found using the link "Supplementary Material" in the journal issue contents page.

\section{References}

1. Diels, O.; Bolm, J. H.; Knoll, W. Justus Liebigs Ann. Chem. 1925, 443, 242;

2. Fringuelli, F.; Taticchi, A. The Diels-Alder Reaction: Selected Practical Methods, Eds.; John Wiley \& Sons: New York, 2002

3. Hamer, J. 1,4-. Cycloaddition Reactions, Academic Press: New York, N. Y., 1967.

4. Kawasaki, M.; Yamamoto, H. J. Am. Chem. Soc. 2006, 128, 16482 https://doi.org/10.1021/ja066726y

5. Liu, B.; Li, K.-N.; Luo, S.-W.; Huang, J.-Z.; Pang, H.; Gong, L.-Z. J. Am. Chem. Soc. 2013, 135, 3323 https://doi.org/10.1021/ja3110472

6. Oscarsson, K.; Oscarson, S.; Vrang, L.; Hamelink, E.; Hallberg, A.; Samuelsson, B. Bioorg. Med. Chem. 2003, 11, 1235 https://doi.org/10.1016/S0968-0896(02)00643-0

7. Zuccarello, G.; Bouzide, A.; Kvarnström, I.; Niklasson, G.; Svensson, S. C. T.; Brisander, M.; Danielsson, H.; Nillroth, U.; Karlén, A.; Hallberg, A.; Classon, B.; Samuelsson, B. J. Org. Chem. 1998, 63, 4898 https://doi.org/10.1021/jo971562c

8. Grange, R. L.; Gallen, M. J.; Schill, H.; Johns, J. P.; Dong, L.; Parsons, P. G.; Reddell, P. W.; Gordon, V. A.; Bernhardt, P. V.; Williams, C. M. Chem. Eur. J. 2010, 16, 8894 https://doi.org/10.1002/chem.200903454

9. Rodgman, A.; Wright, G. F. J. Org. Chem. 1953, 18, 465 https://doi.org/10.1021/jo01133a001

10. Tirri, T.; Aubert, M.; Pawelec, W.; Wilen, C-E.; Pfaendner, R.; Hoppe, H.; Roth, M.; Sinkkonen J. J. Appl. Polym. Sci. 2014, 131, 40413 https://doi.org/10.1002/app.40413

11. Pieber, B.; Martinez, S. T.; Cantillo, D.; Kappe C. O. Angew. Chem. Int. Ed. 2013, 52, 10241 https://doi.org/10.1002/anie.201303528

12. Chaiyaveij, D.; Cleary, L.; Batsanov, A. S.; Marder, T. B.; Shea, K. J.; Whiting, A. Org. Lett. 2011, 13, 3442 https://doi.org/10.1021/ol201188d

13. Chaiyaveij, D.; Batsanov, A. S.; Fox, M. A.; Marder, T. B.; Whiting, A. J. Org. Chem. 2015, 80, 9518 https://doi.org/10.1021/acs.joc.5b01470

14. Allen, S. E.; Walvoord, R. R.; Padilla-Salinas, R.; Kozlowski, M. C. Chem. Rev. 2013, 113, 6234 https://doi.org/10.1021/cr300527g

15. Elwell, C. E.; Gagnon, N. L.; Neisen, B. D.; Dhar, D.; Spaeth, A. D.; Yee, G. M.; Tolman W. B. Chem. Rev. 2017, 117, 2059 https://doi.org/10.1021/acs.chemrev.6b00636

16. Trammell, R.; Rajabimoghadam, K.; Garcia-Bosch I. Chem. Rev. 2019, 119, 2954 https://doi.org/10.1021/acs.chemrev.8b00368 
17. Lal, K.; Rani P. ARKIVOC, 2016, 1, 307

https://doi.org/10.3998/ark.5550190.p009.593

18. Frazier, C. P.; Engelking, J. R.; Read de Alaniz, J. J. Am. Chem. Soc. 2011, 133, 10430 https://doi.org/10.1021/ja204603u

19. Frazier, C. P.; Bugarin, A.; Engelking, J. R.; Read de Alaniz, J. J. Org. Lett. 2012, 14, 3620 https://doi.org/10.1021/ol301414k

20. Samoshin, A. V.; Hawker, C. J.; Read de Alaniz, J. J. ACS Macro Lett. 2014, 3, 753 https://doi.org/10.1021/mz500348y

21. Fodor, R.; Wein, J. J. Chem. Soc. 1948, 684 https://doi.org/10.1039/JR9480000684

22. Zhu, Y.; Shi, Y. Org. Lett. 2013, 15, 1942 https://doi.org/10.1021/ol4005917

23. Jung, D.; Kim, M. H.; Kim J. Org. Lett. 2016, 18, 6300 https://doi.org/10.1021/acs.orglett.6b03166

24. Franzus, B. J. Org. Chem. 1963, 28, 2954 https://doi.org/10.1021/jo01046a004

25. Cohen, S. G.; Zand, R. J. Am. Chem. Soc. 1962, 84, 586 https://doi.org/10.1021/ja00863a017

26. Franzus, B.; Surridge, J. H. J. Org. Chem. 1962, 27, 1951 https://doi.org/10.1021/jo01053a006

27. Gillis, B. T.; Beck, P. E.; J. Org. Chem. 1962, 27, 1947 https://doi.org/10.1021/jo01053a005

28. Menard, F.; Weise, C. F.; Lautens, M. Org. Lett. 2007, 9, 5365 https://doi.org/10.1021/ol7022054

29. Menard, F.; Lautens, M. Angew. Chem. Int. Ed. 2008, 47, 2085 https://doi.org/10.1002/anie.200704708

30. Curini M.; Epifano, F.; Marcotullio M. C.; Rosati O., Heterocycles 2001, 8 ,1599

31. Kiselev, V.D.; Kornilov, D.A.; Kashaeva, E.A.; Potapova, L.N.; Konovalov, A.I. Russ. J. Org. Chem. 2014, 50,489 https://doi.org/10.1134/S1070428014040071

32. Price, B.; Sutherland, I. O.; Williamson, F. G., Tetrahedron 1966, 22, 3477 https://doi.org/10.1016/S0040-4020(01)92536-0

33. Yi, X.; Xi, C. Org. Lett. 2015, 17, 5836 https://doi.org/10.1021/acs.orglett.5b03009

34. Zhang, C.; Jiao, N. Angew. Chem. Int. Ed. 2010, 49, 6174 https://doi.org/10.1002/anie.201001651

35. Gillis, B. T.; Hagarty, J. D. J. Org. Chem. 1967, 32, 330 https://doi.org/10.1021/jo01288a016

36. Wei, Y.; Lemal, D. M.Org. Lett. 2004, 6, 3837 https://doi.org/10.1021/ol040051r

37. Jensen, F.; Foote, C. S. J. Am. Chem. Soc. 1987, 109, 6376 https://doi.org/10.1021/ja00255a024

38. Kiselev, V.D., Kornilov, D.A., Kashaeva, E.A., Potapova, L.N., Krivolapov, D.V., Litvinov, I.A., Konovalov, A.I., Russ. J. Phys. Chem. A 2014, 88, 2073 
https://doi.org/10.1134/S0036024414120152

39. Roy, N.; Lehn, J. M. Chem. - Asian J. 2011, 6, 2419

https://doi.org/10.1002/asia.201100244

40. Bigelow, H. E.; Robinson, D. B Org. Synth. Coll. Vol. 1955, 3, 103.

41. Farhadi, S.; Zaringhadam, P.; Sahamieh, R. Z. Acta Chim. Slov. 2007, 54, 647

This paper is an open access article distributed under the terms of the Creative Commons Attribution (CC BY) license (http://creativecommons.org/licenses/by/4.0/) 